\title{
PENGARUH KEPEMIMPINAN, LINGKUNGAN KERJA, DAN DISIPLIN KERJA TERHADAP KINERJA KARYAWAN
}

\section{(Studi pada pegawai non medis Instalasi Sterilisasi di RS Dr. Kariadi Semarang)}

\author{
Adi Setya Pamungkas
}

Sri Yuni Widowati

Fakultas Ekonomi Universitas Semarang

\author{
Diterima: Mei 2020, Disetujui: Juni 2020, Dipublikasikan: Juli 2020
}

\begin{abstract}
This study was motivated by the decline in targets in the Sterilization Installation of the Hospital Dr. Kariadi Semarang, for that the problem can be formulated is how the Sterilization Installation Section improves employee performance so that the production target is reached. The purpose of this study was to analyze the influence of Leadership, Work Environment and Work Discipline on Employee Performance of the Sterilization Installation at DR. Kariadi Semarang.Data were collected through questionnaire methods using Census techniques for 61 respondents in the Sterilization Installation section. Data processing uses multiple regression analysis, hypothesis testing through $t$ test, model testing with $f$ test, and analysis of the coefficient of determination.The results obtained in this study are the magnitude of the coefficient of determination is 0.547 which means that $54.7 \%$ of the variables of Leadership, Work Environment and Work Discipline have a positive and significant effect on Employee Performance.
\end{abstract}

Keywords: Leadership, Work Environment, Work Discipline, Employee Performance.

\begin{abstract}
ABSTRAK
Penelitian ini dilatar belakangi oleh terjadinya penurunan target di Instalasi Sterilisasi Rumah Sakit DR. Kariadi Semarang, untuk itu dapat dirumuskan masalahnya adalah bagaimana upaya Bagian Instalasi Sterilisasi meningkatkan Kinerja Karyawan agar target sasaran mutu tercapai. Tujuan penelitian ini adalah untuk menganalisis pengaruh Kepemimpinan, Lingkungan Kerja dan Disiplin Kerja terhadap Kinerja Karyawan Bagian Instalasi Sterilisasi di Rumah Sakit DR. Kariadi Semarang. Data dikumpulkan melalui metode kuisioner dengan menggunakan teknik Sensus terhadap 61 orang responden bagian Instalasi Sterilisasi. Pengolahan data menggunakan analisis regresi berganda, pengujian hipotesis melalui uji t, pengujian model dengan uji $\mathrm{f}$, serta analisis koefisien determinasi. Hasil yang diperoeh dalam penelitian ini adalah besarnya nilai koefisien determinasi adalah 0,547 yang artinya 54,7\% variabel Kepemimpinan, Lingkungan Kerja dan Disiplin Kerja berpengaruh positif dan signifikan terhadap Kinerja Karyawan.
\end{abstract}

Kata kunci : Kepemimpinan, Lingkungan Kerja,Disiplin Kerja,Kinerja Karyawan.

\section{PENDAHULUAN}

Keberhasilan pelaksanaan organisasi publik sangat ditentukan oleh kualitas sumber daya manusia. Hal ini menunjukkan bahwa sumber daya manusia mempunyai peran yang sangat penting dalam mencapai tujuan pembangunan. Oleh karena itu peningkatan kualitas sumber daya manusia sangat diperlukan agar semua karyawan dan pimpinan memiliki sikap dan perilaku yang berintikan pengabdian, kejujuran, tanggung 
jawab, disiplin, keadilan dan kewibawaan sehingga dapat memberikan pelayanan dan pengayoman serta dapat memberikan kesejahteraan lahir batin kepada masyarakat. Untuk mewujudkan kualitas sumber daya manusia dalam suatu organisasi, peranan pimpinan mempunyai andil yang cukup. Semakin tingginya tingkat pendidikan masyarakat menyebabkan masyarakat semakin sadar akan pentingnya kualitas. Masyarakat cenderung menuntut pelayanan kesehatan yang lebih baik dan cepat. Hal ini menimbulkan persaingan yang semakin ketat. Rumah sakit merupakan bagian integral dari keseluruhan system pelayanan kesehatan yang melayani pasien dengan berbagai jenis pelayanan Kesehatan mempunyai peranan besar dalam meningkatkan derajat hidup masyaraka,dalam pemberian pelayanan kesehatan yang optimal di rumah sakit diperlukan sumber daya yang berkualitas, dengan menggunakan sumber dayayang ada diharapkan rumah sakit dapat menghasilkan suatu out put yang maksimal berupa produk atau jasa untuk meningkatkan pelayanan. Untuk masalah-maslaah tersebut haruslah disadari bahwa keberhasilan rumah sakit antara lain disebabkan sumber daya manusia, sehingga sumber daya manusia dipandang sebagai asset rumah sakit, bahkan merupakan investasi rumah sakit apabila tenaga tersebut merupakan tenaga yang terampil.

Kebehasilan pelayanan kesehatan di rumah sakit tidak terlepas dari berbagai faktor pelayanan bukan hanya dari segi Keperawatan saja tetapi juga adanya SDM non medis lain yang ikut membantu dalam terlaksananya pelayanan yang baik. Oleh karena itu, agar dapat terus mengembangkan dirinya dan untuk kelangsungan hidup organisasi, manajemen rumah sakit perlu melakukan peningkatan kinerja karyawan. Dalam hal ini peningkatan kinerja karyawan yang diharapkan adalah agar mampu meningkatkan kinerjanya semaksimal mungkin untuk memberikan pelayanan yang memuaskan. Keberhasilan suatu organisasi sangat di pengaruhi oleh kinerja karyawannya. Setiap organisasi maupun perusahaan akan selalu berusaha untuk meningkatkan kinerja karyawannya dengan harapan apa yang menjadi tujuan perusahaan tercapai. Untuk mencapai hasil tersebut di perlukan faktor yang mempengaruhi pencapaian kinerja.

Rumah Sakit Kariadi merupakan Rumah Sakit yang memiliki VISI "Menjadi Rumah Sakit Terbaik di Indonesia”. Secara Struktural Rumah Sakit Kariadi merupakan Unit Pelaksana Teknis (UPT) di Lingkungan Departemen Kesehatan. Rumah Sakit Kariadi berlokasi di J1. Dr. Sutomo No 16 Semarang. Rumah Sakit Kariadi memiliki 
fasilitas yang lengkap antara lain: Rawat Jalan, Rawat Inap, Rawat Intensif, Rawat Darurat, Unit Penyakit Jantung dan Pembuluh Darah, Unit Geriatri, Paviliun Garuda dan Rehabilitasi Medik. serta Fasilitas Penunjang antara lain: Radiologi, Pusat Diagnostik Klinik, Laboratorium,Farmasi Dan juga Instalasi Sterilisasi alat medis.

Berikut ini adalah data pencapaian target mutu pelayanan Instalasi Sterilisasi alat Medis di RS Dr.Kariadi Semarang Tahun 2017 :

Tabel 1

Tabel Pencapaian Target Mutu Instalasi Sterlisisai tahun 2014 - 2018

\begin{tabular}{|l|l|l|l|l|}
\hline No & Tahun & $\begin{array}{l}\text { Ketida ksesuai an } \\
\text { alat bedah (Target } \\
<25 \%)\end{array}$ & $\begin{array}{c}\text { Kepuas an pelangg an } \\
\text { internal (Target } \\
80 \%)\end{array}$ & $\begin{array}{c}\text { Monitoring } \\
\text { alkes Single Use } \\
\text { di Re Use }\end{array}$ \\
\hline 1 & 2014 & $26 \%$ & $77 \%$ & $79 \%$ \\
\hline 2 & 2015 & $25 \%$ & $77 \%$ & $79 \%$ \\
\hline 3 & 2016 & $25 \%$ & $74 \%$ & $75 \%$ \\
\hline 4 & 2017 & $25 \%$ & $72 \%$ & $73 \%$ \\
\hline 5 & 2018 & $24 \%$ & $73 \%$ & \\
\hline
\end{tabular}

Sumber: Target Sasaran Mutu Instalasi Sterilisasi RSUP DR kariadi tahun 2014 -2018

Berdasarkan tabel 1 menunjukkan Ketidak Tercapaiannya target Sasaran Mutu Di Instalasi RS Dr.Kariadi Semarang Pada tahun 2014 - 2018. Terlihat bahwa Indikator target Ketidaksesuaian Instrumen bedah tidak memenuhi target yang di inginkan hal ini di akibatkan karna terjadinya kehilangan Instrumen pada saat operan alat kotor yang dapat di akibatkan karna alat tertinggal di Linen/kain bedah,yang mengakibatkan jumlah alat tidak sesuai dengan jumlah standar yang ada di cheklis instrument.Begitu juga dengan kendala kepuasan pelanggan internal yang di akibatkan karena terlalu lama karyawan dalam menangani alat yang akan d sterilkan,yang mengakibatkan terkendalanya proses pendistribusian alat yang sudah steril ke ruangan/kamar bedah dan juga kendala dengan adanya mesin Error pada saat proses sterilisasi yang berakibat mundurnya waktu penyelesaian proses sterilisasi dan pendistribusian alat.Dan juga adanya kendala alat single Use di Re Use yang di akibatkan karena pada saat penerimaan alat Single Use,jumlah alat dan monitoring single Use tidak sesuai dan juga monitoring Singe Use tanggal tidak sesuai dengan yang tertera di alat Single Use.Kemampuan kepemimpinan sangat diperlukan untuk 
meningkatkan kinerja karyawan. selain itu lingkungan kerja sangat penting untuk diperhatikan oleh manajemen perusahaan.

Adapun rumusan masalah dalam penelitian ini adalah :

1. Bagaimana pengaruh Kepemimpinan terhadap kinerja Kinerja Pegawai non medis Instalasi Sterilisai di RS Dr.Kariadi Semarang?

2. Bagaimana pengaruh Lingkungan kerja terhadap kinerja Kinerja Pegawai non medis Instalasi Sterilisai di RS Dr.Kariadi Semarang?

3. Bagaimana pengaruh Disiplin kerja terhadap kinerja Kinerja Pegawai non medis InstalasI Sterilisasi di RS Dr.Kariadi Semarang?

\section{TINJAUAN PUSTAKA}

\section{Kinerja}

Kinerja merupakan penampilan hasil kerja pegawai baik secara kuantitas maupun kualitas. Kinerja dapat berupa penampilan kerja perorangan maupun kelompok.Menurut Sedarmayanti (2007:70), menyatakan bahwa kinerja merupakan sistem yang digunakan untuk menilai dan mengetahui apakah seorang karyawan telah melaksanakan pekerjaannya secara keseluruhan, atau merupakan perpaduan dari hasil kerja (apa yang harus dicapai seseorang) dan kompetensi (bagaimana seseorang mencapainya).

Pada prinsipnya kinerja merupakan sikap mental yang mempunyai kebiasaan meningkatkan kualitas pekerjaan dalam melaksanakan kerja apa saja yang dilakukan. Untuk meningkatkan kinerja pegawai, sangat dibutuhkan :

\section{Sifat}

Kepemimpinan, Lingkungan kerja yang baik, dan Disiplin kerja yang menjadi tolak ukur baik buruknya karyawan. MenurutKartono (2008:34)Kepemimpinan adalah sifat, kebiasaan, temperamen, watak dan kepribadian yang membedakan seorang pemimpin dalam berinteraksi dengan orang lain). Berdasarkan teori di atas dapat dilihat bahwa factor kepemimpinan merupakan salah satu faktor yang paling memengaruhi tingkat kinerja individu karyawan, dimana karyawan banyak 
belajar dari bagaimana pemimpin itu bersikap. Pemimpin juga diharap dapat menjadi penghubung antar karyawan, dapat memberikan informasi yang jelas dan dapat mengambil keputusan secara bijak. Menurut Kartono (2008:34), bahwa gaya kepemimpinan terdiri dari lima indikator yaitu: berpengaruh dalam gaya kepemimpinan untuk menentukan keberhasilan menjadi seorang pemimpin yang berhasil, serta di tentukan oleh kepribadian pemimpin.

\section{Kebiasaan}

Kebiasaan memegang peranan kepemimpinan sebagai penentu pergerakan perilaku seorang yang menggambarkan segala tindakan yang dilakukan sebagai pemimpin yang baik.

\section{Temperamen}

Gaya perilaku yang cara khasnya dalam memberi tanggapan dalam berinteraksi dengan orang lain.

4. Watak

Watak seorang pemimpin yang lebih subyektif dapat menjadi penentu bagi keunggulan seorang pemimpin dalam mempengaruhi keyakinan, ketekunan, daya tahan dan keberanian.

5. Kepribadian

Keprbadian seseorang pemimpin menentukan keberhasilan yang di tentukan oleh sifat-sifat atau karakteristik kepribadian yang dimilikinya.

Kepemimpinan merupakan salah satu faktor yangpaling memengaruhi tingkat kinerja individu karyawan,dimana karyawan banyak belajar dari bagaimanapemimpin itu bersikap. Pemimpin juga diharap dapatmenjadi penghubung antar karyawan, dapatmemberikan informasi yang jelas dan dapat mengambilkeputusan secara bijak.Berdasarkan Penelitian yang di lakukan oleh Alwi Suddin (2010), bahwa Kepemimpinan berpengaruh terhadap Kinerja Pegawai.Serta didukung oleh penelitian Any Isvandiary (2018),bahwa Kepemimpinan Berpengaruh terhadap Kinerja Pegawai.

H1: Kepemimpinan berpengaruh terhadap Kinerja Karyawan 


\section{Lingkungan Kerja}

Menurut Sedarmayanti (2001:1) Lingkungan Kerja adalah keseluruhan alat perkakas dan bahan yang dihadapi, lingkungan sekitar di mana seseorang bekerja, metode kerja serta pengaturan kerjanya baik sebagai perseorangan maupun kelompok. Lingkungan kerja yang baik atau kondisi kerja yang mampu memberikan motivasi untuk bekerja akan berpengaruh terhadap semangat karyawan dalam bekerja. Pengertian lingkungan kerja adalah segala sesuatu yang ada di sekitar para pekerja dan dapat memengaruhi dirinya dalam menjalankan tugas-tugas yang dibebankan, misalnya kebersihan, musik, dan penerangan. Penelitian yang di lakukan oleh Ni Made Diah Yudiningsih,Fridayana Yudiatmaja,Ni Nyoman Yulianthini (2016),yang menyatakan bahwa Lingkungan Kerja berpengaruh positif terhadap Kinerja Pegawai.Serta didukung oleh penelitian Audrey Josephine dan Dhyah Harjanti (2017),yang menyatakan bahwa Lingkungan Kerja berpengaruh terhadap Kinerja Pegawai.

H2: Lingkungan Kerja berpengaruh terhadap kinerja Karyawan

\section{Disiplin Kerja}

Menurut Hasibuan (2004), berpendapat bahwa kedisiplinan adalah kesadaran dan kesediaanseseorang menaati semua peraturan perusahaan dan norma-norma sosialyang berlaku. Berdasarkan pengertian diatas disimpulkan bahwa disiplinkerja merupakan suatu sikap, tingkah laku, dan perbuatan yang sesuaidengan peraturan baik tertulis maupun tidak tertulis, dan bila melanggarakan adas anksi atas pelanggarannya. Penelitian yang di lakukan oleh Agung Setiawan(2013),bahwa Disiplin Kerja tidak berpengaruh terhadap Kinerja Pegawai.Sedangkan penelitian menurut Feru Liawandy,dkk (2014), bahwa Disiplin Kerja berpengaruh terhadap Kinerja Pegawai.

H3: Disiplin Kerja berpengaruh terhadap kinerja karyawan 


\section{METODE PENELITIAN}

\section{Populasi dan Sampel Penelitian}

Pada penelitian ini yang menjadi Objek penelitian adalah karyawan di bagian Instalasi Sterilisasi Rumah sakit Dr.kariadi Semarang yang berlokasi di Jl. DR.Sutomo No.16, Semarang, Jawa Tengah yang merupakan rumah sakit tipe ARujukan Nasional.

Dengan menggunakan seluruh jumlah responden yaitu sebanyak 61 responden. Metode pengambilan sampel ini menggunakan teknik Sensus.

\section{Analisis Data}

Model Persamaan Regresi linear berganda tersebut adalah:

$$
Y=b_{1} X_{1}+b_{2} X_{2}+b_{3} X_{3}
$$

Keterangan :

Y : Kinerja

$\mathrm{b}_{1} \mathrm{X}_{1}$ :Koefisien regresi dari Kepemimpinan

$\mathrm{b}_{2} \mathrm{X}_{2}$ :Koefisien regresi dari Lingkungan Kerja

$\mathrm{b}_{3} \mathrm{X}_{3}$ :Koefisien regresi dari Disiplin Kerja

Uji statistik $\mathrm{t}$ pada dasarnya menunjukkan seberapa jauh pengaruh satu variabel independen secara individual dalam menerangkan variasi variabel dependen, dengan langkahlangkah sebagai berikut:

a) Jika probabilitas $(\operatorname{Sig} \mathrm{t})>\alpha(0,05)$, maka Ho diterima,artinya tidak ada pengaruh yang signifikan secara individu dari variabel independen (X) terhadap variabel dependen (Y).

b) Jika probabilitas $(\operatorname{Sig} t)<\alpha(0,05)$, maka Ho ditolak, artinya ada pengaruh yang signifikan secara individu dari variabel independen (X) terhadap variabel dependen $(\mathrm{Y})$. 
Uji Ketepatan model dilakukan dengan Uji F. Uji F pada dasarnya menunjukkan apakah semua variabel bebas yang dimasukkan dalam model mempunyai pengaruh secara bersama-sama terhadap variabel terkait.

a) Jika probabilitas $($ Sig F) $>\alpha(0,05)$, maka Ho diterima,artinya tidak ada pengaruh yang signifikan secara Bersama-sama dari variabel independen (X) terhadap variabel dependen $(\mathrm{Y})$.

b) Jika probabilitas (Sig F) $<\alpha(0,05)$, maka Ho ditolak,artinya ada pengaruh yang signifikan secara Bersama-sama dari variabel independen (X) terhadap variabel dependen $(\mathrm{Y})$.

Koefisien determinasi $\left(\mathrm{R}^{2}\right)$ pada intinya mengukur seberapa jauh kemampuan model dalam menerangkan variasi variabel dependen. Nilai koefisien determinasi adalah antara nol (0) dan satu (1).

\section{HASIL DAN PEMBAHASAN}

Hasil uji instrument penelitian menunjukkan bahwa masing-masing item pertanyaan yang mewakili variabel Kepemimpian (5 item pertanyaan), Lingkungan Kerja (5 item pertanyaan), dan Disiplin Kerja (5 item pertanyaan) dinyatakan valid karena dari hasil korelasi antara hasil jawaban responden pada tiap item pertanyaan dengan skor total di dapat hasil yang signifikan, yaitu nilai $r_{\text {hitung }} \geq r_{\text {tabel. Sedangkan }}$ hasl uji reliabilitas memperlihatkan nilai Cronbach's Alpha semua variabel $\geq 0,60$, sehingga dapat disimpulkan bahwa indikator yang digunakan dapat di percaya atau handal untuk digunakan sebagai alat ukur variabel.

Uji asumsi klasik yang di persyaratkan sebelum uji regresi berganda menunjukkan model regresi dalam penelitian ini telah terpenuhi, yaitu data berdistribusi normal karena $\mathrm{P}_{\text {value }}$ (Asymp.Sig.) dari semua pengujian adalah > 0,05, tidak terjadi heteroskedaitas karena titik-titik pada grafik tidak bisa membentuk pola tertentu yang jelas, dimana titik-titik menyebar di atas dan di bawah angka 0 pada sumbu Y, serta bebas dari multikolinearitas nilai tolerance masing-masing variabel 
independen berada diatas 0,1 dan nilain VIF masing-masing variabel independen berada di bawah 10 .

\section{Analisis Regresi Linier Berganda}

Analisis regresi linier berganda digunakan untuk melihat pengaruh antara Kepemimpinan, Lingkungan Kerja dan Disiplin kerja terhadap Kinerja Karyawan. Hasil analisis regresi berganda dengan menggunakan program SPSS versi 22 adalah sebagai berikut :

Tabel 1

Hasil Analisis Regresi Linier Berganda

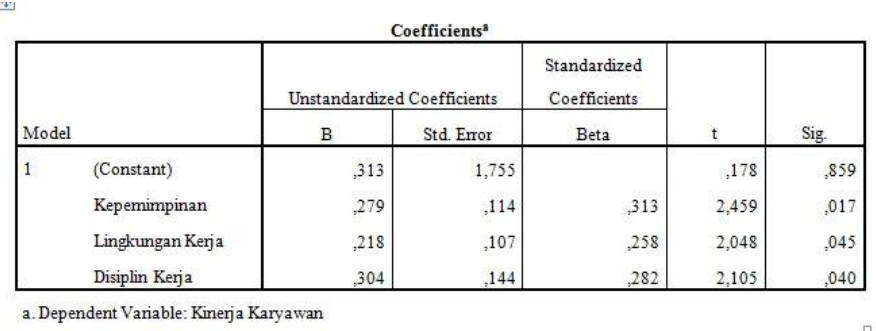

Sumber: Data Primer diolah, 2018

Berdasarkan hasil regresi pada tabel diatas, dapat disimpulkan persamaan regresi dalam penelitian ini sebagai berikut :

$$
Y=0,313 X_{1}+0,258 X_{2}+0,282 X_{3}
$$

Berdasarkan hasil persamaan regresi diatas maka dapat disimpulkan bahwa :

a. Koefisien regresi untuk variabel Kepemimpinan sebesar 0,313 bernilai positif, artinya semakin baik disiplin kerja yang diterapkan maka akan semakin meningkatkan Kinerja Karyawan.

b. Koefisien regresi untuk variabel Lingkungan Kerja sebesar 0,258 bernilai positif, artinya semakin baik lingkungan kerja yang diberikan maka akan semakin meningkatkan Kinerja Karyawan.

c. Koefisien regresi untuk variabel Disiplin Kerja sebesar

0,282 bernilai positif, artinya semakin baik kompensasi yang diberikanmaka akan semakin meningkatkan kinerja karyawan. 


\section{Uji Ketepatan Model (Uji F) Tabel 2}

\section{Hasil Uji F}

\begin{tabular}{|c|c|c|c|c|c|c|}
\hline \multicolumn{7}{|c|}{ ANOVA } \\
\hline Mo & & Sum of Squares & df & Mean Square & $\mathrm{F}$ & Sig. \\
\hline \multirow[t]{3}{*}{1} & Regression & 422,393 & 3 & 140,798 & 25,193 &, $000^{\circ}$ \\
\hline & Residual & 318,557 & 57 & 5,589 & & \\
\hline & Total & 740,951 & 60 & & & \\
\hline
\end{tabular}

b. Predictors: (Constant), Disiplin Kerja, Lingkungan Kerja, Kepemimpinan

Sumber: Data Primer diolah, 2018

Berdasarkan tabel 2 di ketahui bahwa nilai $F_{\text {hitung sebesar 25,193 dan nilai }}$ $\mathrm{P}_{\text {value }}$ sebesar 0,000. Karena $\mathrm{F}_{\text {Hitung }}(25,193)>\mathrm{F}_{\text {tabel }}(2,53)$ dan nilai $\mathrm{P}_{\text {value }}$ (Sig.) $=0,000<0,05$ sehingga hasil uji $\mathrm{F}$ pada tabel 2 tersebut disimpulkan bahwa model regresi yang digunakan dalam penelitian ini adalah " sesuai / cocok(fit)"

\section{Koefisien Determinasi}

Koefisien determinasi ini digunakan untuk mengetahui seberapa besar kemampuan variabel bebas dalam menerangkan variabel terikat. Nilai determinasi ditentukan dengan Adjusted R Square.

Tabel 3

\section{Koefisien Determinasi}

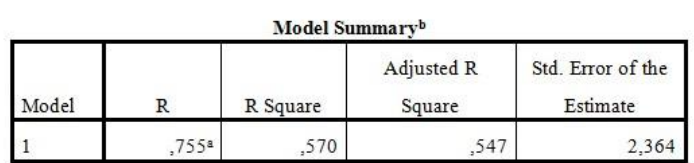

a. Predictors: (Constant), Disiplin Kerja, Lingkungan Kerja,Kepemimpinan

b. Dependent Variable: Kinerja Karyawan

Sumber: Data Primer diolah, 2018

Berdasarkan tabel 4.17 hasil Koefisien Determinasi diatas, dapat diketahui bahwa nilai Koefisien Determinasi (Adjusted $R$ Square) diperoleh sebesar 0,547 atau 54,7\%. Hal ini berarti seluruh variabel bebas (Kepemimpinan, Lingkungan Kerja dan Disiplin Kerja) berpengaruh terhadap variabel Kinerja Karyawan sebesar 54,7\%, sedangkan sisanya, yaitu sebesar $45,3 \%$ dipengaruhi oleh faktor-faktor lain yang tidak dijelaskan dalam penelitian ini. 


\section{HASIL DAN PEMBAHASAN}

\section{Kepemimpinan}

Berdasarkan hasil pengujian, diperoleh nilai $t_{\text {hitung }}$ antara Kepemimpinan $\left(\mathrm{X}_{1}\right)$ terhadap Kinerja Karyawan (Y) sebesar 2,459> nilai $t_{\text {tabel }}$ yaitu 2,001 dan nilai signifikansi sebesar $0,017<$ taraf signifikasi $a=5 \%(0,05)$. Hal ini berarti bahwa terdapat pengaruh yang positif dan siginfikan antara kepemimpinan $\left(\mathrm{X}_{1}\right)$ terhadap kinerja karyawan (Y). sehingga hipotesis pertama diterima. Berdasarkan hasil pengujian hipotesis menunjukkan bahwa Kepemimpinan berpengaruh positif dan signifikan terhadap Kinerja Karyawan.Semakin baik arahan yang dilakukan pemimpin terhadap karyawannya, maka semakin tinggi juga tingkat produktivitas para karyawan. Hasil ini didukung penelitian yang dilakukan oleh Alwi Suddin (2010) serta penelitian yang dilakukan oleh Any Isvandiary (2018) yang menyatakan hasil Kepemimpinan berpengaruh positif dan signifikan terhadap Kinerja Karyawan.

\section{Lingkungan Kerja}

Berdasarkan hasil pengujian, diperoleh nilai $t_{\text {hitung }}$ antara Lingkungan Kerja $\left(\mathrm{X}_{2}\right)$ terhadap Kinerja Karyawan (Y) sebesar 2,048> nilai $t_{\text {tabel }}$ yaitu 2,001 dan nilai signifikansi sebesar $0,045<$ taraf signifikasi $a=5 \%(0,05)$. Hal ini berarti bahwa terdapat pengaruh yang positif dan siginfikan antara lingkungan kerja $\left(\mathrm{X}_{2}\right)$ terhadap kinerja karyawan (Y). sehingga hipotesis kedua diterima. Berdasarkan hasil pengujian hipotesis menunjukkan bahwa Lingkungan Kerja berpengaruh positif dan signifikan terhadap Kinerja Karyawan. Semakin mendukung sarana dan prasarana kerja maka akan baik pula Kinerja Karyawan. Hasil ini didukung penelitian yang dilakukan oleh Ni Made Diah Yudiningsih,Fridayana Yudiaatmaja, Ni Nyoman Yulianthini(2016) serta penelitian yang dilakukan oleh Audrey Josephine dan Dhyah Harjanti (2017) yang menyatakan bahwa Lingkungan Kerja berpengaruh positif dan signifikan terhadap Kinerja Karyawan.

\section{Disiplin Kerja}

Berdasarkan hasil pengujian, diperoleh nilai $t_{\text {hitung }}$ antara Disiplin $\operatorname{Kerja}\left(\mathrm{X}_{3}\right)$ terhadap kinerja karyawan $(\mathrm{Y})$ sebesar 2,105> nilai $\mathrm{t}_{\text {tabel }}$ yaitu 2.001 dan nilai signifikansi sebesar $0,040<$ taraf signifikasi $a=5 \%(0,05)$. Hal ini 
berarti bahwa terdapat pengaruh yang positif dan siginfikan antara Disiplin $\operatorname{Kerja}\left(\mathrm{X}_{3}\right)$ terhadap Kinerja Karyawan $(\mathrm{Y})$. sehingga hipotesis ketiga diterima. Berdasarkan hasil pengujian hipotesis menunjukkan bahwa Disiplin kerja berpengaruh positif dan signifikan terhadap Kinerja Karyawan. Semakin disiplin karyawan kepada perusahaan maka karyawan semakin baik dalam meningkatkan hasil kinerjanya. Hasil ini didukung penelitian yang dilakukan Sutrisno , Azis Fathoni , Maria Magdalena Minarsih(2016) serta penelitian yang dilakukan oleh Feru Liawandy,dkk (2014) yang menyatakan bahwa Disiplin Kerja berpengaruh positif dan signifikan terhadap Kinerja Karyawan.

\section{KESIMPULAN DAN SARAN}

\section{Kesimpulan}

1. Terdapat pengaruh Positif dan signifikan antara Kepemimpinan (X1) terhadap Kinerja Karyawan (Y).

2. Terdapat pengaruh Positif dan signifikan antara Lingkungan Kerja (X2) terhadap Kinerja Karyawan (Y).

3. Terdapat pengaruh Positif dan signifikan antara Disiplin Kerja (X3) terhadap Kinerja Karyawan (Y).

\section{Saran}

1. Disarankan agar pimpinan bisa lebih peduli terhadap karyawannya dengan terjun langsung dan memantau alur pekerjaan di lapangan dan memberikan arahan langsung kepada para karyawannya.

2. Disarankan agar perusahaan memperhatikan suara bising yang menggangu didalam ruangan kerja dan memberikan alat keamanan pelindung diri khusus untuk para karyawanya,dengan memberikan alat pelindung telinga atau ruangan dengan peredam suara, sehingga karyawan dapat bekerja dengan nyaman,aman dan berkonsentrasi dalam menyelesaikan pekerjaannya.

3. Disarankan agar pimpinan bisa memberikan arahan dan sanksi Surat peringatan kepada karyawan yang datang terlambat agar tidak terulang lagi 
lain waktu dan karyawan harus bekerja sesuai SPO yang sudah di tentukan agar tercapainya produktivitas yang tinggi.

\section{DAFTAR PUSTAKA}

Banni, Maslan. 2013. Pengaruh Disiplin dan Motivasi Terhadap Kinerja Pegawai PT. PLN (Persero) Wilayah Kalimantan Timur Area Samarinda. Publikasi ilmiah Universitas Mulawarman. Vol 1 No 1.

Cahyo Adinugroho, 2015, "Pengaruh Kepemimpinan dan Disiplin Kerja terhadap Kinerja Pegawai pada Dinas Pendidikan Kota Bengkulu, Universitas Negeri Jakarta.

Dubrin, Andrew J., 2006, "Leadership" (Terjemahan), Edisi Ketiga, Prenada Media: Jakarta.

Ni Made Diah Yudiningsih, Fridayana Yudiaatmaja, Ni Nyoman Yulianthini,"Pengaruh Lingkungan Kerja Dan Disiplin Kerja Terhadap Kinerja Pegawai”. E-Journal Bisma Universitas Pendidikan Ganesha Jurusan Manajemen (Volume 4 Tahun 2016).

Endang, Sri Handayani. 2006. Pengaruh Disiplin Kerja Dan Motivasi Kerja Terhadap Kinerja Karyawan Koperasi yang Tergabung Pada Pusat Koperasi Simpan Pinjan Artho Kuncoro Karanganyar. Tesis Program Magister Manajemen Program Pasca Sarjana Universitas Slamet Riyadi Surakarta.

Ghozali Imam, 2009, “Aplikasi Analisis Multi8variate dengan Program SPSS", Cetakan Keempat, Semarang, Badan Penerbit Universitas Diponegoro. .

Hasibuan, Malayu S.P. 2008, "Manajemen Sumber Daya Manusia”, Jakarta : Penerbit Bumi Aksara, Ghozali.

Hidayat, C.N. (2015). Pengaruh Lingkungan Kerja dan Motivasi Kerja Terhadap Kinerja KaryawanKantor PT. Keramik Diamond Industries. AGORA 3(2),7883.

Lidia Lusri Dan Hotlan Siagian (2017) "Pengaruh Motivasi Kerja Terhadap Kinerja Karyawan Melalui Kepuasan Kerja Sebagai Variabel Mediasi Pada Karyawan Pt. Borwita Citra Prima Surabaya. Jurnal Agora Vol. 5, No. 1,

Audrey Josephine dan Dhyah Harjanti S.E.,M.Si. (2017) "Pengaruh Lingkungan Kerja Terhadap Kinerja Karyawan Pada Bagian Produksi Melalui Motivasi Kerja Sebagai Variabel Intervening Pada PT. Trio Corporate Plastic (Tricopla)". Jurnal AGORA Vol. 5, No. 3

Any Isvandiari (2018) "Pengaruh Kepemimpinan Dan Disiplin Kerja Terhadap Kinerja Karyawan Pada Pt Central Capital Futures Cabang Malang”. Jurnal Jibeka Volume 12, No 1,(17-22) 
Feru Liawandy, Dkk Jurnal Jom FEKON Vol. 1 No. 2 Oktober 2014 "Pengaruh disiplin kerja dan lingkungan kerja terhadap kinerja karyawan bagian produksi PT. Nafal Tiara Abadi Pekanbaru".

Karono, Kartii, 2008 : “Pemimpin dan Kepemimpinan”, Jakarta : PT Raja Grafindo Persada.

Mangkunegara, A. P. (2013). Manajemen Sumber Daya Manusia Perusahaan. Bandung: PT. Remaja Rosdakarya.

Mangkunegara, AP., 2001 "Manajemen Sumber Daya Manusia Perusahaan”, Edisi Baru, Remaja Resda Karya Bandung.

Mathis, Robert L. dan Jacson, 2011 : "Manajemen Sumber Daya Manusia” Edisi 9, Jakarta : Salemba Empat.

Nitisemito, Alex, S. 2000. Manajemen Personalia. Cetakan Ketiga. Jakarta: Ghalia Indonesia.

Rahmawanti, N.P., B. Swasto, \& A. Prasetya. (2014). Pengaruh Lingkungan Kerja Terhadap Kinerja Karyawan (Studi pada Karyawan Kantor Pelayanan Pajak Pratama Malang Utara). Jurnal Administrasi Bisnis 8(2), 1-9

Regina Aditya Reza, 2015 : "Pengaruh Gaya Kepemimpinan, Motivasi dan Disiplin Kerja terhadap Kinerja Karyawan Studi pada PT Sinar

Sedarmayanti, 2011, “ Manajemen Sumber Daya Manusia, Reformasi Birokrasi dan Manajemen Pegawai Negeri Sipil”, Cetakan Ke Lima, Bandung, : PT Refika Aditama.

Siagian , P. Sondang. 2004 . Teori- Teori Motivasi. Jakarta: PT. Rineka Cipta.

Simamora, Henry. 2004. Manajemen Sumber Daya Manusia Edisi Ketiga. Yogyakarta: STIE YKPN.

Singarimbun, Masri dan Sofian Effendi, 2006, "Metode Penelitian Survei (Editor)", LP3ES, Jakarta.

Sugiyono, 2009, "Metode Penelitian Bisnis (Pendekatan Kuantitatif; Kualitatif dan R \& D)", Bandung, Alfabeta.

Suwardi, \& Utomo, J. (2011). Pengaruh Motivasi Kerja, Kepuasan Kerja, dan Komitmen Organisasional terhadap Kinerja Pegawai ( Studi Pada Pegawai Setda Kabupaten Pati ). Analisis Manajemen, 5(1), 75-86.

Suwondo, D. I., \& Sutanto, E. M. (2015). Hubungan lingkungan kerja, disiplin kerja, dan kinerja karyawan. Jurnal Manajemen Dan Kewirausahaan, 17(2), 135144.

Veithzal Rivai, 2011, "Manajemen Sumber Daya Manusia untuk Perusahaan dari Teori ke Praktik, pt Raja Grafindo, Jakarta 